\title{
CRISE DA RACIONALIDADE E SUSTENTABILIDADE NO MERCADO DE COMBUSTÍVEIS NO ESTADO DA PARAÍBA
}

\author{
Ana Celecina Lucena da Costa Rangel \\ Mestre em Desenvolvimento e Meio Ambiente pela Universidade Federal da Paraíba (UFPB). \\ Especialização em Gestão ambiental pela Faculdades Integradas de Jacarepaguá (FIJ) \\ Email: anaceluc@gmail.com
}

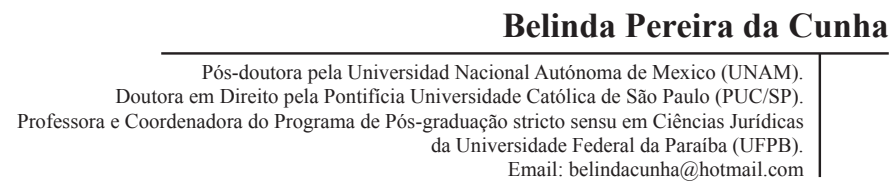

Renan Aversari Câmara

Mestre em Desenvolvimento e Meio Ambiente pela Universidade Federal da Paraíba (UFPB).

Professor na graduação em Direito da Universidade Estadual da Paraíba (UEPB).

Email: a.c.renan@gmail.com

\section{RESUMO}

O artigo pretende apresentar uma análise introdutiva da temática, objetivando examinar alguns dos principais aspectos relativos à produção e consumo da gasolina e do etanol, em âmbito nacional e regional, particularmente no estado da Paraíba, contrapondo com a crise ambiental posta hodiernamente, embasados nos ensinamentos de Enrique Leff. Aponta, conjuntamente: o crescimento do número de veículos em circulação no Brasil e na Paraíba, no período de 1998 a 2016, relacionando-o tanto ao crescimento de emissão dos gases do efeito estufa quanto aos custos de produção da gasolina e etanol, bem como ao preço para o consumidor final; à formação dos preços desses combustíveis, com particular ênfase na tributação; e à sustentabilidade da produção e uso do etanol. Para isso, realizou-se uma pesquisa com cunho exploratório-descritivo, comparativo, qualiquantitativo e bibliográfico-documental, assumindo como técnica de análise de dados a denominada análise SWOT. Conclui-se, entre outros aspectos, que a produção do etanol oferece maiores vantagens quando comparada com a da gasolina, devendo ser estimulado o seu consumo massificado. Contudo, cabe ao setor sucroalcooleiro tornar o mercado 
sustentável, principalmente em termos socioambientais. Permanecer do modo como está só agravará os sintomas da atual crise ambiental mundial.

Palavras-chave: Meio ambiente; Crise ambiental; Matriz energética; Sustentabilidade.

\title{
RATIONALITY CRISIS AND SUSTAINABILITY IN THE MARKET OF FUELS IN THE STATE OF PARAÍBA
}

\begin{abstract}
The article aims to present an introductory analysis of the theme, aiming to examine some of the key aspects of the production and consumption of gasoline and ethanol, at national and regional levels, particularly in the state of Paraiba, contrasting with the environmental crisis set in our times, based on the teachings Enrique Leff. Points together: the growing number of vehicles in circulation in Brazil and Paraiba from 1998 to 2016, relating to the growth of emissions of greenhouse gases; gasoline and ethanol production costs and the price to the end consumer; the formation of prices of these fuels, particularly with an emphasis on taxation; and the sustainable production and use of ethanol. For this, a survey was conducted with descriptive exploratory nature, comparative, qualitative and quantitative and bibliographic and documentary, taking as data analysis technique called a SWOT analysis. It is concluded, among other things, that the ethanol production offers major advantages when compared with gasoline and must be stimulated their mass consumption. However, it is the sugarcane industry make sustainable market, especially in social and environmental terms. Stay the way it is it will only aggravate the symptoms of today's global environmental crisis.
\end{abstract}

Keywords: Environment; Environmental crisis; Energy Matrix; Sustainability. 


\section{INTRODUÇÃO}

Uma das questões refletivas da crise ambiental da atualidade e há muito debatida é a pertinente à preservação e utilização racional dos recursos naturais, especificamente quanto ao uso de combustíveis fósseis, dentre os quais se releva o petróleo. O emprego frequente desta fonte de energia não renovável dá-se especialmente por sua conversão em gasolina, para a indústria e para os veículos automotores.

Como reflexos negativos sobre o ecossistema, originados pelo uso indiscriminado deste insumo, pode-se mencionar a emissão, para a atmosfera, dos denominados gases de efeito estufa (GEE), provocadores, entre outros efeitos, do aquecimento global e da contaminação dos solos e da água.

Os resultados já compilados e anunciados pelo Ministério da Ciência, Tecnologia e Inovação (MCTI, 2014), relativos às estimativas de emissões de gases do efeito estufa, demonstram um crescimento destas, especialmente no setor energético (devido, entre outros fatores, à queima de combustíveis e emissões fugitivas da indústria de petróleo, gás e carvão mineral), de 187,739 milhões de toneladas, em 1990, para 446,154 milhões de toneladas em 2012.

Diante disso, a racionalidade econômica, decorrente de uma economia neoliberal, acaba por permitir práticas danosas, poluentes e degradantes ao meio ambiente, uma vez que as regras de mercado estão sempre a se utilizar de meios menos dispendiosos, visando maximizar os lucros, independente se o resultado econômico também desencadeie um risco ambiental mediato ou imediato.

A máxima dos agentes econômicos envolvidos neste mercado é: internalizar os ganhos e externalizar os custos, pela indução ao consumo de bens e serviços danosos não só à preservação e proteção do meio ambiente, bem como a seus respectivos recursos naturais.

Uma das alternativas viáveis a uma mudança estrutural nesse setor e promovedora de desenvolvimento sustentável dá-se pelo estímulo e permuta na produção e consumo do petróleo, gás e carvão mineral pelos combustíveis renováveis e de baixa emissão de carbono, a exemplo do etanol.

Como bem assevera Grisoli (2011), diversas iniciativas estão em desenvolvimento com o fito de indicar fatores de sustentabilidade aos biocombustíveis, de forma que possam cumprir sua proposição de suprir a 
matriz energética do setor, contornando as externalidades negativas que venham a impactar o meio ambiente.

De fato, e conforme se depreende de diversos estudos na área, este recurso natural, conjuntamente com outras modalidades de recursos renováveis, apresenta-se econômica, social e ambientalmente mais viável em comparação à persistência na utilização de recursos não renováveis, como o petróleo, que, embora promovam o crescimento econômico, comprometem a continuidade da existência de uma vida sadia no planeta.

A ciência moderna permitiu um considerável aporte de conhecimento científico que demonstra a fragilidade e os limites da terra, que levou "milhões de anos para produzir os seus variados recursos naturais", porém, não mais suporta o nível atual de contaminação a que está submetida (NEGRET, 2001, p. 107).

Assim, este artigo pretende apresentar uma análise introdutiva da temática, objetivando examinar alguns dos principais aspectos relativos à produção e consumo da gasolina e do etanol, em âmbito nacional e regional, particularmente no estado da Paraíba, contrapondo com a crise ambiental posta hodiernamente, tendo como base os ensinamentos de Enrique Leff.

Dentre os objetivos específicos, apresentam-se os seguintes:

- Apresentar o crescimento do número de veículos em circulação no Brasil e na Paraíba, no período de 1998 a 2016 (apenas os modelos movidos a gasolina e etanol), no intuito de relacionar esses dados com o crescimento de emissão dos gases do efeito estufa;

- Delinear os custos de produção da gasolina e do etanol, bem como o preço ao consumidor final;

- Enunciar a formação dos preços desses combustíveis, em particular do etanol, com particular ênfase na tributação (Imposto sobre Operações Relativas à Circulação de Mercadorias e sobre Prestações de Serviços de Transporte Interestadual e Intermunicipal e de Comunicação (ICMS), principalmente);

- Analisar a sustentabilidade da produção e uso do etanol, com base na análise SWOT (sigla em inglês para Strength, Weakness, Opportunities e Threats); e

- Traçar um paralelo entre esses pontos e a atual crise ambiental no setor energético.

A pesquisa, com cunho exploratório-descritivo, comparativo, qualiquantitativo e bibliográfico-documental (GIL, 2008), assumiu como 
técnica de análise de dados a denominada análise SWOT, pela investigação, respectivamente, das forças, fraquezas, oportunidades e ameaças relacionadas à produção do etanol (JANNUZZI; GOMES, 2009), demonstrando-se o potencial deste combustível para a redução das externalidades produzidas pelo consumo da gasolina, bem como seus aspectos negativos, de forma a dar concordância lógica com o arcabouço teórico exposto no trabalho, focado em aspectos pertinentes e adequados ao estudo, a exemplo da racionalidade ambiental, crise ambiental, sustentabilidade, economia ecológica, entre outros.

Acredita-se, por fim, que a pesquisa contribui cientificamente de forma empírica e multifacetada, influenciando na percepção dos setores econômicos eleitos, do consumidor final, do Estado ou, de uma forma global, da sociedade.

\section{ANÁLISE COMPARATIVA DO CONSUMO DE COMBUSTÍVEIS NO BRASIL E NO ESTADO DA PARAÍBA}

Em um primeiro plano, faz-se mister elencar a quantidade de automóveis em circulação no Brasil, dado necessário para demonstrar a escala e importância do estudo.

Para tanto, foi selecionada, dentre os números atualizados até dezembro de 2016, fornecidos pelo Departamento Nacional de Trânsito (DENATRAN), apenas a classe de automóveis com tecnologia flex, excluindo-se motocicletas, tratores, ônibus, caminhões, entre outros. Desse modo, para esta colação, selecionaram-se exclusivamente os veículos automotores classificados como categoria B (carros) pelo Código Trânsito Brasileiro (CTB).

Isto posto, tem-se que o número de carros em circulação no Brasil, no ano de 1998, totalizava 17.819.843; em dezembro de 2016, atingiu o patamar de 51.296.982 (DENATRAN, 2017). Neste período, no estado da Paraíba, o número passou de 124.187 para 483.927 automóveis (DENATRAN, 2017).

É válido salientar que até o ano de 2003, quando a frota nacional era de cerca de 23 milhões de automóveis (169.440 na Paraíba), ainda não estavam em circulação os carros com tecnologia flex, tendo o consumidor que optar, exclusivamente, por veículos movidos a álcool ou a gasolina. Anteriormente à implementação daquela tecnologia, a indústria automobilística do etanol acabava sendo supressiva. 
Com o fim da crise do petróleo e o aumento da extração nacional no inicio dos anos 90, houve um incentivo sem precedentes à indústria petrolífera brasileira. Tal fato acabou por esvanecer a produção do etanol até à inserção (e consolidação) no mercado dos automóveis com tecnologia flex. Com este advento tecnológico, o consumo do etanol tornou-se mais tangível; todavia, não suplantou o da gasolina, como constatado a seguir.

Proporcionalmente ao aumento da frota de automóveis, houve o aumento da emissão do dióxido de carbono $\left(\mathrm{CO}_{2)}\right.$ e dos gases do efeito estufa, conforme dados da Organização para a Cooperação e Desenvolvimento Econômico (OECD).

Assim, refletindo um fenômeno mundial, o Brasil passou de cerca de 271 milhões de toneladas de $\mathrm{CO}_{2}$, em 1998, para 476 milhões de toneladas de $\mathrm{CO}_{2}$ em 2014, restando notória a linearidade da participação deste setor no volume de emissões estimado. De idêntico modo, embora com percentual bem menos expressivo, os gases do efeito estufa passaram de 709.934 mil toneladas, em 1998, para um pouco mais de 1 milhão de toneladas no ano de 2012 (OECD, 2017).

No ano de 2016, segundo dados da Agência Nacional do Petróleo, Gás Natural e Biocombustíveis (ANP), o volume de etanol vendido no território nacional chegou a 14,586 bilhões de litros, ao passo que foram consumidos mais de 43,019 bilhões de litros de gasolina do tipo C. Já no estado da Paraíba, no ano de 2015, o patamar de consumo do etanol chegou aos 131 milhões de litros, contrapondo-se aos 662 milhões de litros de gasolina (ANP, 2017). Revela-se, assim, uma enorme discrepância no padrão de consumo das referidas matrizes energéticas.

Todavia, segundo dados extraídos da ANP (2013), a partir da inserção e consolidação dos motores com tecnologia flex no mercado, em 2004, detectou-se a elevação do consumo do etanol hidratado em todos os estados brasileiros.

Atualmente, constata-se considerável diminuição nas vendas devido a políticas de indução ao consumo da gasolina, por diretrizes economicistas influenciadas pela indústria do petróleo. Outrossim, a crise no setor sucroalcooleiro e a falta de investimentos necessários para a sua superação, a partir do ano de 2009, causaram o aumento dos preços em todas as fases do produto, bem como a retração no consumo do etanol, impedindo que a produção acompanhasse a demanda (ANP, 2013).

Isto acaba por evidenciar que o consumo de determinado produto, ainda que ambientalmente menos impactante, não se constitui como 
uma questão de ética, mas, de fato, como uma condição econômica.

Acerca desta constatação, Leff (2004b) ressalta um aspecto relevante da crise ambiental atual, em que inexiste qualquer consideração do meio ambiente por parte do agente econômico que, visando apenas maximizar os lucros a curto prazo, extrai e transforma destrutivamente os recursos naturais, estimulando o hiperconsumo, direcionado a mercados e/ou a produtos específicos, mesmo que sejam insustentáveis.

A racionalidade econômica impôs um padrão de produção e consumo tendentes a satisfazer necessidades enganosas, criadas pelo próprio sistema econômico, decorrentes da superexploração dos recursos renováveis ou não (LEFF, 2004b), corrompendo o homem e a sociedade em sua relação intrínseca com o ambiente.

Todavia, faz-se premente uma quebra de paradigma do setor energético, pela implementação de incentivos massivos à produção e consumo do etanol e de outros insumos ecologicamente corretos, substitutivos da gasolina, não só pelo fato de aquele ser um recurso natural renovável, mas principalmente em função da sustentabilidade inerente a ele, sob todos os aspectos (social, econômico e ambiental), os quais serão adiante explicitados.

Exemplificativamente, no concernente ao custo de produção, segundo a Associação dos Plantadores de Cana-de-Açúcar da Paraíba (ASPLAN-PB, 2017), o custo médio de produção do etanol brasileiro ainda é o menos dispendioso do planeta, girando em torno de US\$ 0,18 (cerca de $\mathrm{R} \$$ 0,56, com a cotação do dólar comercial de fevereiro de 2017). Contudo, cabe ressaltar que o custo de produção do etanol é variável a cada safra.

Conforme a Petróleo Brasileiro S.A (PETROBRAS, 2017), o custo de produção da gasolina do tipo $\mathrm{C}$ ocorre em torno de 30\% (trinta por cento) do valor final de venda, cerca de R\$1,125 o litro (ANP, 2017). Considerando-se ainda o grau médio de eficiência energética do etanol em comparação com a gasolina do tipo C, qual seja, 70\% (setenta por cento), já contabilizado o custo de produção, percebe-se a viabilidade econômica da substituição do segundo pela primeira modalidade de combustível.

Ademais, além do preço bruto da produção do etanol ser consideravelmente inferior ao da gasolina, o valor percentual relativo à tributação desses combustíveis também é muito divergente, a exemplo do que ocorre no estado da Paraíba (1996).

Em relação à gasolina, incidem os seguintes tributos: o Programa de Integração Social e a Contribuição para Financiamento da Seguridade 
Social (PIS/COFINS), no percentual de $8 \%$ (oito por cento), a Contribuição de Intervenção no Domínio Econômico (CIDE), no percentual de 2\% (dois por cento) e o Imposto sobre Operações Relativas à Circulação de Mercadorias e sobre Prestações de Serviços de Transporte Interestadual e Intermunicipal e de Comunicação (ICMS), no percentual de 29\% (vinte e nove por cento), além dos custos do etanol anidro, no percentual de $14 \%$ (quatorze por cento) e das operações de distribuição e/ou revenda, no percentual de 17\% (dezessete por cento). (PETROBRAS, 2017). Já sobre o etanol, não há incidência de PIS/COFINS nem da CIDE, mas apenas o ICMS, a uma alíquota de $25 \%$ (vinte e cinco por cento).

Com o preço bruto de produção, somam-se os dividendos a título de lucro de distribuição e revenda, bem como a tributação, para chegar-se ao preço final do combustível para o consumidor.

Especificamente no estado da Paraíba, os dados divulgados pela Agência Nacional do Petróleo (2017) corroboram com as informações anteriormente citadas, pois, para a composição do preço final do etanol, percebe-se que os custos relativos à tributação e à produção são substancialmente inferiores, quando comparados aos da gasolina. E ainda que as despesas referentes à distribuição e à revenda do etanol estejam em patamar acima daqueles praticados para a gasolina, custam, em média, um real a menos por litro.

O Brasil ocupa posição de destaque na produção do etanol de cana-de-açúcar, principalmente pelo balanço energético mais favorável, bem como pelos baixos custos de produção, especificados anteriormente, o que lhe garante o título de maior exportador desse biocombustível (GRISOLI, 2011).

Apesar disso, a título exemplificativo, saliente-se que no estado da Paraíba, no mês de fevereiro de 2017, segundo a ANP (2017), o preço médio do etanol era de $\mathrm{R} \$ 2,864$, ao passo que o preço médio da gasolina naquele período estava cotado a $\mathrm{R} \$ 3,749$. Igualmente ocorre nos demais estados, onde, em oposição ao custo de produção, o preço destinado ao consumidor final do etanol opera acima dos $70 \%$ do preço final da gasolina, direcionando, desta forma, para o consumo deste.

Desta feita, verifica-se a predileção pelo consumo da gasolina do tipo $\mathrm{C}$, em detrimento do etanol hidratado, permitindo-se inferir, assim, que, apesar de o custo da sua produção ser mais atrativo, em termos financeiros, a majoração do preço ao consumidor final acaba desestimulando o seu consumo. 
As influências externas do mercado, bem como as pressões de grupos econômicos e seus interesses na indústria do petróleo, tornam a oferta final ao consumidor da gasolina mais aprazível, coadunando-se com a lógica do mercado de acumulação capitalista, indutora e modeladora da demanda e do atendimento das "necessidades" da sociedade (LEFF, 2004a).

Essa condução manietada da produção e do consumo, não restrita ao setor energético, revela o comportamento inescrupuloso dos agentes econômicos, condizente com um tratamento mercantilizado dos bens ambientais e revelador de uma crise ambiental sem precedentes, que compromete as condições de existência da humanidade.

Diante disso, Enrique Leff propõe a redefinição do sistema econômico vigente para uma economia ecológica, que se atente criticamente para a "degradação ecológica e energética resultante dos processos de produção e consumo", e sujeite "o intercâmbio econômico às condições do metabolismo geral da natureza" (LEFF, 2004a, p. 44).

\section{ANÁLISE DA SUSTENTABILIDADE DA PRODUÇÃO E CONSU- MO DO ETANOL}

Dentre os efeitos decorrentes da produção do etanol, denominados externalidades, podem-se enumerar os mais relevantes, de forma a legitimar a indução do seu consumo no mercado. Isto posto, o que se busca é a manutenibilidade do correto equilíbrio ambiental, conforme os ditames elencados no art. 225 da Constituição Federal (BRASIL, 1988). Doutra forma, não existiria razão para o favorecimento de um produto tão danoso ao ambiente quanto o atualmente predominante, derivado do petróleo.

Neste aspecto, Paixão e Fonseca (2011, p. 53) estabelecem, com propriedade, o significado do verbete sustentabilidade, sob a ótica econômica, que "implica boa gestão dos recursos naturais, associada à minimização dos custos provocada pelo uso destes recursos para garantir perenidade ao processo produtivo".

Visto isso, torna-se imperioso conhecer os principais aspectos (positivos e negativos), no que diz respeito à produção do etanol, e as medidas a serem tomadas de forma a elevar o grau de sustentabilidade.

Conforme enunciam Paixão e Fonseca (2011), a maior preocupação do setor sucroalcooleiro brasileiro consiste na eliminação da queima da cana-de-açúcar na fase agrícola, pois, apesar de ser a forma de manejo 
mais favorável ao trabalhador rural, recurso predominante nesta fase da produção, alude a externalidades ambientais negativas de grande relevância, tais como a destruição e degradação de ecossistemas, danos às características físicas do solo, liberação de gases e partículas poluentes, além de emissão de GEE na atmosfera (PAIXÃO E FONSECA, 2011).

Ainda em conformidade com os mesmos autores, a mudança procedimental acaba por resultar em fator economicamente vantajoso para a sua produção, pois, além de a colheita da cana in natura representar uma resolução em potencial para o problema das externalidades ambientais negativas geradas no processo da queima, resulta em outros ganhos econômicos significativos, porque, a exemplo do bagaço, outras sobras e resíduos da planta, como pontas e palhas, podem ser utilizadas como insumo na cogeração de energia elétrica (PAIXÃO e FONSECA, 2011).

No tocante à liberação de GEE, o volume produzido e depositado na atmosfera inerente à combustão de biomassa residual da cana in natura colhida para produção de energia elétrica é equivalente à emissão relativa da queima daquela biomassa no campo, quando da colheita. Desta forma, a alternativa da queima para a produção de eletricidade é preferível, visto que se mostra como uma externalidade positiva e importante, a qual é completamente inexistente na opção da queima no campo (PAIXÃO e FONSECA, 2011).

Neste sentido, no ano de 2002 o Governo Federal oficializou o Programa de Incentivo às Fontes Alternativas de Energia Elétrica (PROINFA), determinando que a contratação, pelas Centrais Elétricas Brasileiras S.A. (ELETROBRAS), de pelo menos 3.300 megawatts, seja de energia proveniente de fontes renováveis.

Segundo a ÚNICA, em 2008 o setor sucroalcooleiro brasileiro, utilizando o processo de geração de energia elétrica através da queima da biomassa da cana, foi responsável, no âmbito desse programa, por negociar quase 2.500 megawatts de energia elétrica (ÚNICA, 2009).

Isso mostra que os subprodutos derivados da cana-de-açúcar têm elevado sua participação na matriz energética e, desde 2007, tornaram-se a segunda fonte primária de energia elétrica no país (PAIXÃO e FONSECA, 2011).

De maneira complementar, o emprego das estruturas de tráfego controlado (ETC's), em substituição à queima da cana, viabiliza a colheita da cana in natura em terrenos com aclive de até $40 \%$ e consome menos diesel por hectare, diminuindo as emissões de gases precursores de efeito 
estufa e de gases poluentes e particulados.

Afora tais considerações, pode-se enaltecer a eliminação do chumbo tetraetila da gasolina, pela sua substituição por etanol hidratado.

No que tange à utilização da água, considerável parte da irrigação é feita pela chuva (MACEDO, 2007). Deste fato, extrai-se que a pouca demanda por água é um fator importante para a redução de impactos ambientais, o que acaba por evitar arraste de nutrientes, resíduos de agrotóxicos, perdas de solo etc. (JANNUZZI e GOMES, 2009). Outro aspecto a ser citado é a total utilização dos resíduos da produção (vinhaça e cinzas) no processo de irrigação da lavoura, reduzindo a necessidade de consumo de água.

Acontece que existem exceções a essa prática, como quando ocorre o incremento de áreas para o plantio da cana, especialmente para regiões com deficit pluviais acentuados. A irrigação da cana-de-açúcar é uma prática comum nos estados da região Nordeste; no entanto, a produção, na fase industrial, figura como a maior consumidora de água do meio ambiente (JANNUZZI E GOMES, 2009).

A utilização do vinhoto como fertilizante, embora reduza o consumo de água, detém o potencial de provocar a salinização dos lençóis freáticos pela lixiviação de seus elementos, assim como ocasiona a nitrificação do solo. Desta maneira, embora o vinhoto seja um subproduto orgânico e que contém água e nutrientes minerais, necessita ter o seu uso controlado (JANNUZZI E GOMES, 2009).

Como forma de contornar tais situações, são enunciadas algumas medidas voltadas à sustentabilidade do setor sucroalcooleiro no quesito água. Deve-se levar em consideração a prática da reconversão dos sistemas de irrigação por superfície, que figura como o principal método de irrigação utilizado no país, mostrando um aproveitamento muito baixo. No caso das regiões com deficit pluviométricos, a irrigação pode apresentar-se de maneira ambiental e economicamente viável, desde que utilizados métodos que primem pela eficiência, tais como os que empregam equipamentos de maior facilidade de controle, os que indicam manejo adequado dos sistemas de irrigação por superfície e os que incluem sistemas para maior uniformidade de aplicação de água (por aspersão) e irrigação localizada (por gotejamento e microaspersão, por exemplo) (JANNUZZI E GOMES, 2015).

Também deve ser levado em consideração o fomento da redução da coleta, uso e lançamento da água. Cerca de $90 \%$ (noventa por cento) do 
seu uso ocorrem em quatro processos: lavagem de cana, condensadores/ multijatos na evaporação e vácuos, resfriamento de dornas e condensadores de álcool. O uso de água na lavagem da cana, por volta de 5 metros cúbicos por tonelada, pode ser reduzido com a limpeza a seco. Há a possibilidade de se atingir valores próximos a 1 metro cúbico de água por tonelada de cana, com otimização da reutilização e uso da água residual adicionada do vinhoto para a irrigação (denominada de fertirrigação) (JANNUZZI E GOMES, 2015).

Tanto a umidade quanto a compactação do solo são fatores diretamente relacionados ao tempo de vida útil da lavoura canavieira. Os sistemas de controle de tráfego e a prática do plantio direto são resolúveis para os referidos parâmetros de produção. Ao serem aplicados, proporcionam uma maior umectação do solo, maior eficiência no aproveitamento da precipitação pluviométrica, diminuição na compactação dos solos e na ocorrência de enxurradas (perdas de solo, nutrientes e água), bem como a diminuição no uso de herbicidas e fertilizantes (JANNUZZI E GOMES, 2015).

Outra problemática decorrente do plantio da cana é a relativa à expansão das áreas de produção, pois, conforme Nassar et al (2010), as mudanças do uso do solo decorrentes da expansão do plantio da cana ocorrem quando esta cultura substitui uma área antes destinada a outras atividades ou vegetação. Segundo os pesquisadores, tal expansão ocorre principalmente em áreas de pastagens, outrora destinadas à produção agropecuária ou outras culturas, reduzindo os efeitos sobre as vegetações nativas.

Ainda em Nassar et al (2010), segundo levantamento realizado entre os anos de 2005 e 2008, a produção do etanol cresceu de 16 para 27 bilhões de litros por ano, o que acarretou um aumento de 2,4 milhões de hectares de área de cultivo de cana. Dentro deste avanço, a substituição direta de áreas nativas foi de 9.700 hectares e de 181.000 hectares, indiretamente.

O estado de São Paulo saiu na vanguarda para solucionar o avanço do plantio de cana sobre áreas nativas, criando o zoneamento agroambiental, que disciplina a expansão e a ocupação do solo, inclusive sobre a criação de corredores de biodiversidade (COSTA; GUILHOTO, 2011).

Jannuzzi e Gomes (2009, p. 14) assim estabelecem o significado de corredor de biodiversidade: 
É uma área estrategicamente destinada à conservação ambiental na escala regional. Ele compreende uma rede de áreas protegidas, entremeada por áreas com variáveis graus de ocupação humana. O manejo é integrado para ampliar a possibilidade de sobrevivência de todas as espécies, a manutenção de processos ecológicos e evolutivos e o desenvolvimento de uma economia regional baseada no uso sustentável dos recursos naturais. Em áreas de alta fragmentação florestal, como a Mata Atlântica, os Corredores de Biodiversidade também têm por objetivo a recuperação e conexão dos fragmentos de florestas. Assim, espera-se vencer o isolamento das áreas protegidas e ampliar a conectividade dos ambientes nativos, permitindo o trânsito das espécies de flora e fauna entre os remanescentes.

Diante disso, verifica-se que sob o aspecto ambiental a produção de etanol é sustentável, se comparada a outras matrizes energéticas, e que as intercorrências no setor podem ser adequadamente sanadas, a depender da adoção de medidas mitigadoras por parte dos seus produtores. Já no aspecto social, e considerando-se o progresso tecnológico, que potencialmente provoca reduções de emprego pela utilização de mecanização agrícola, verifica-se que a expansão do setor envolve o aumento global e melhoria na qualidade dos empregos (VIEIRA; LIMA; BRAGA, 2017).

De acordo com o $2^{\circ}$ Relatório de Sustentabilidade do setor sucroenergético, publicado pela União da Indústria de Cana de Açúcar (ÚNICA), o setor sucroalcooleiro desempenha papel estratégico no fomento de postos de trabalho em nível nacional. Conforme a Relação Anual de Informações Sociais (RAIS) do Ministério do Trabalho e Emprego (MTE), em 2008 foram contabilizados 1.283.258 de empregos formais, sendo: 481.662 de trabalhadores relacionados ao cultivo da cana-de-açúcar; 561.292 inseridos nas fábricas de açúcar em bruto; 13.791 destinados ao refino e moagem de açúcar; e, por fim, 226.513 trabalhadores operando na produção de etanol (ÚNICA, 2015).

Por estimativa, o relatório ainda afirma que para cada emprego direto são gerados dois indiretos. Desta maneira, atinge-se a marca de 3,85 milhões de pessoas alocadas em empregos relacionados à produção da cana-de-açúcar. Pontua-se, ainda, que tais empregos diretos compõem uma grande diversidade de funções, cargos e especializações. Em média, uma usina padrão tem cerca de 400 cargos, variando desde o trabalho manual até funções bastante qualificadas, seja nas áreas técnicas e/ou administrativas (ÚNICA, 2015).

Em complementação aos efeitos diretos e indiretos da geração de 
emprego e renda pelo setor sucroalcooleiro, o relatório acima mencionado, apresentando dados do IBGE de 2009 quanto aos impactos socioeconômicos, enaltece que, no respeitante ao trabalhador de atividades manuais, o índice de empregos formais atingiu o patamar de 79,6\%. Isto posto, insta colacionar que o impacto social da atividade canavieira no Brasil não deve ser avaliado somente pelos empregos gerados. De igual importância, notese que o setor, alastrado por boa parte do território nacional, funciona como um descentralizador de renda e contribui para a distribuição regional da riqueza, uma vez que esta atividade está presente em 25 dos 26 estados brasileiros, abrangendo 1.042 municípios e somando quase $20 \%$ da totalidade dos municípios brasileiros (ÚNICA, 2015).

Quanto à escolaridade, a média dos assalariados na lavoura canavieira ainda é baixa, embora tenha se verificado um aumento relevante nos últimos anos. Ainda de acordo com os dados do IBGE de 2009, o período de atividade escolar desses trabalhadores é, em média, de 4 a 5 anos. Este resultado explicita que o setor sucroalcooleiro é responsável pela inclusão no mercado de trabalho de uma massa de mão de obra que dificilmente seria absorvida em outros ramos da atividade econômica. Neste quesito, pode-se enaltecer que o aumento da mecanização implica em um crescimento na demanda por profissionais mais qualificados. Para exemplificar, tem-se que uma colhedora mecânica substitui o trabalho de cerca de oitenta pessoas com baixa qualificação; no entanto, necessita de doze trabalhadores com capacitação técnica em automação e mecanização (ÚNICA, 2015).

Acerca da massa salarial, ainda no $2^{\circ}$ Relatório de Sustentabilidade do setor sucroenergético publicado pela ÚNICA, destaca-se que a escolaridade influi diretamente nos salários do trabalhador do setor. Desta forma, para avaliar o enquadramento da remuneração dos trabalhadores nas plantações de cana, faz-se necessária uma comparação em relação aos empregados de outras culturas. Diante disso, entre os anos de 2007 a 2009 constatou-se que o trabalhador dos canaviais detinha um rendimento médio de $\mathrm{R} \$ 721,58$, abaixo apenas do trabalhador das fazendas de soja (média de $\mathrm{R} \$ 905,33)$, onde predomina o alto grau de mecanização, e que, portanto, demandam mão de obra mais qualificada. Noutras culturas (café, arroz, milho e mandioca), o trabalhador rural possui pior remuneração, comparativamente ao empregado do setor sucroalcooleiro (ÚNICA, 2015).

Ainda assim, cabe destacar que há poucos estudos e cuidados pormenorizados por parte das empregadoras do ramo, relativamente ao 
cumprimento das normas de saúde e segurança do trabalho, principalmente quanto ao cumprimento da Norma Regulamentadora (NR) n. ${ }^{\circ} 31$ (VEIGA FILHO, 2007), do Ministério do Trabalho e Emprego, que trata especificamente dos trabalhadores que laboram na agricultura (BRASIL, 2005).

Por todo o exposto, a análise SWOT realizada por Jannuzzi e Gomes (2009) pontua alguns aspectos acerca das vantagens, desvantagens, soluções sustentáveis e potencialidades de risco a serem contornadas pelo setor sucroalcooleiro, dentre os quais cabe destacar:

Vantagens:

- Custo total de produção reduzido, em relação ao custo de produção da gasolina;

- Menor incidência tributária, comparativamente à gasolina;

- Nenhuma ou pouca necessidade de irrigação;

- Reutilização/reciclagem de grande parte da água usada para o plantio;

- Reciclo integral dos efluentes industriais (vinhoto, torta de filtro e água residual);

- Legislação de controle e de proibição da prática da queima;

- Maior preservação dos solos em relação a outras culturas;

- Disponibilidade de terras;

- Menor uso de defensivos/fertilizantes em relação a outras culturas (fertirrigação e otimização);

- Zoneamento agroambiental no estado de SP;

- Fomento de postos de trabalho em nível nacional;

- Maior formalização dos contratos de trabalho;

- Menor necessidade de qualificação profissional; e

- Média do rendimento salarial superior à de outros produtos do agronegócio nacional

Desvantagens:

- Preço final ao consumidor opera acima dos $70 \%$ do preço final da gasolina;

- Alterações estruturais do solo (perdas de água, nutrientes, solo, salinização, acidez);

- Alta captação de água durante a fase industrial;

- Poluição atmosférica (poluentes e fuligens), decorrente das 
queimadas e da mecanização agrícola;

- Falhas de fiscalização (queimadas e vinhoto);

- Compactação do solo;

- Salinização e contaminação dos lençóis e mananciais (vinhoto, fertilizantes e defensivos agrícolas);

- Enxurradas e assoreamento;

- Fragmentação de habitats e redução de biodiversidade; e

- Falta de cumprimento das normas de saúde e segurança do trabalho no setor.

Soluções sustentáveis:

- Estímulo à competitividade interna e externa frente ao mercado petrolífero;

- Plantio direto;

- Uso de ETC's (pressupõe colheita da cana in natura);

- Agricultura de precisão;

- Tecnologia da informação;

- Uso controlado do vinhoto;

- Corredores de biodiversidade;

- Redução da coleta, uso e lançamento d'água;

- Melhoramento genético;

- Hidrólise enzimática e ácida;

- Concentração térmica e biodigestão do vinhoto;

- Zoneamento agroambiental nacional;

- Instituição, no âmbito laboral, de Serviço Especializado em Segurança e Saúde no Trabalho Rural (SESTR) e de Comissão Interna de Prevenção de Acidentes do Trabalho Rural (CIPATR), atendidas as especificidades da Norma Regulamentadora n. ${ }^{\circ}$ 31, do MTE (BRASIL, 2005).

Potencialidades de risco a serem contornadas:

- Diminuição do monopólio das áreas agrícolas utilizadas para a produção de etanol;

- Efeitos cumulativos do uso do solo e de implementos agrícolas;

- Depleção de recursos hídricos: aumento da demanda por irrigação em áreas com déficit hídrico e do uso industrial de água; 
- Aumento do uso de defensivos agrícolas e fertilizantes inorgânicos;

- Deslocamento de culturas e pastagens;

- Riscos de degradação e queima de áreas de reservas; e

- Maior qualificação profissional dos trabalhadores.

\section{CONSIDERAÇÕES FINAIS}

Observado o cenário socioeconômico e ambiental em que se encontra inserida a produção e o consumo do etanol, sinteticamente analisado neste artigo, pode-se afirmar com serenidade que tanto a produção quanto o consumo deste produto oferece mais vantagens quando comparado com os combustíveis de origem fóssil, como a gasolina.

Embora o etanol seja um recurso natural renovável, a busca de melhorias nas etapas de produção, em especial no aspecto socioambiental, de modo a torná-la ainda mais sustentável, faz com que aquela fonte de energia possua o potencial de redução dos impactos ambientais decorrentes de uma matriz de transporte global majoritariamente composta por combustíveis derivados do petróleo, a exemplo da gasolina, podendo, assim, tornar-se competitiva frente a esta.

Para isso, é preciso salientar o papel relevante do Estado que, zelando pela proteção ambiental, deve elaborar e executar políticas públicas ambientais que visem ao desenvolvimento sustentável no setor energético, não apenas minorando a carga tributária para a produção e consumo do etanol, como também desestimulando atividades potencialmente lesivas ao meio ambiente, a exemplo da produção e consumo da gasolina e, dessa forma, incentivar práticas ambientalmente sustentáveis.

Assim, utilizando-se desta ferramenta, é possível que o Estado consiga induzir uma prática "verde" das atividades econômicas, promovendo o desenvolvimento sustentável e também a proteção do meio ambiente.

Além disso, faz-se necessária uma mudança cultural da sociedade quanto à conscientização e mobilização de frentes sustentáveis de consumo. Obviamente, o papel das empresas do setor e do Governo nessa área será relevante para que as iniciativas particulares de recusa ou boicote ao consumo da gasolina possam ser efetivamente tomadas.

Por fim, importa promover a descontinuidade do estímulo à produção e consumo daquela energia não renovável que, no formato atual, 
revela uma das nuances da crise ambiental mundial, cujos axiomas fundamentais estão na deturpação dos valores, na degradação ambiental e na maximização exacerbada dos lucros.

\section{REFERÊNCIAS}

ASSOCIAÇÃO DOS PLANTADORES DE CANA-DE-AÇÚCAR DA PARAÍBA. Custo do etanol no Brasil ainda é o mais baixo do mundo. Disponível em: <http://asplanpb.com.br/2014/11/10/custo-do-etanol-nobrasil-ainda-e-o-mais-baixo-do-mundo/>. Acesso em: 01 mar. 2017.

BRASIL. Agência Nacional do Petróleo, Gás Natural e Biocombustíveis. Consumo de combustíveis no Brasil caiu 4,5\% na comparação entre 2015 e 2016. Disponível em: <http://www.anp.gov.br/wwwanp/noticias/3585consumo-de-combustiveis-no-brasil-caiu-4-5-na-comparacao-entre-2016e-2015>. Acesso em: 01 mar. 2017.

BRASIL. Agência Nacional do Petróleo, Gás Natural e Biocombustíveis. Dados estatísticos. Disponível em: <http://www.anp.gov.br/wwwanp/dados-estatisticos>. Acesso em: 01 mar. 2017.

BRASIL. Agência Nacional do Petróleo, Gás Natural e Biocombustíveis. Evolução do mercado de combustíveis e derivados: 2000-2012. Rio de Janeiro: ANP, 2013.

BRASIL. Agência Nacional do Petróleo, Gás Natural e Biocombustíveis. Síntese dos preços praticados - Brasil. Disponível em: <http://anp.gov.br/ preco/prc/Resumo_Semanal_Combustiveis.asp>. Acesso em: 01 mar. 2017.

BRASIL. Constituição da República Federativa do Brasil de 1988. Disponível em: <http://www.planalto.gov.br/ccivil_03/Constituicao/Constituicao.htm>. Acesso em: 01 mar. 2017.

BRASIL. Departamento Nacional de Trânsito. Estatísticas da frota de veículos - 2016. Disponível em: <http://www.denatran.gov.br/index.php/estatistica/261-frota-2016>. Acesso em: 01 mar. 2017. 
BRASIL. Lei n. ${ }^{\circ}$ 9.503, de 23 de setembro de 1997. Institui o Código de Trânsito Brasileiro. Disponível em: <http://www.planalto.gov.br/ccivil 03/LEIS/L9503Compilado.htm>. Acesso em: 01 mar. 2017.

BRASIL. Ministério da Ciência, Tecnologia e Inovação. Estimativas anuais de emissões de gases de efeito estufa no Brasil. 2. ed. Brasília, DF, 2014.

BRASIL. Ministério do Trabalho e Emprego. Norma Regulamentadora 31 - Segurança e saúde no trabalho na agricultura, pecuária, silvicultura, exploração florestal e aquicultura. Disponível em: $<\mathrm{http}$ ://www.fiocruz. $\mathrm{br} /$ biosseguranca/Bis/manuais/legislacao/NR-31.pdf $>$. Acesso em: 01 mar. 2017.

BRASIL. Petróleo Brasileiro S.A. Gasolina: composição de preços ao consumidor. Disponível em: <http://www.petrobras.com.br/pt/produtos-e-servicos/composicao-de-precos/gasolina/>. Acesso em: 01 mar. 2017.

COSTA, Cinthia Cabral da; GUILHOTO, Joaquim José M. O papel da tributação diferenciada dos combustíveis no desenvolvimento econômico do estado de São Paulo. Economia Aplicada. Ribeirão Preto-SP, v. 15, n. 3, p. 369-390, 2011.

GIL, Antonio Carlos. Métodos e técnicas de pesquisa social. 6 ed. São Paulo: Atlas, 2008.

GRISOLI, Renata Patrícia Soares. Comparação das emissões de gases de efeito estufa no ciclo de vida do etanol de cana-de-açúcar no Brasil e os critérios da diretiva europeia para energias renováveis. 2011. 112 p. Dissertação (Mestrado em Energia) - Universidade de São Paulo, São Paulo. 2011.

JANNUZZI, Gilberto de Martinho; GOMES, Rodolfo D. M. Aspectos da sustentabilidade ambiental da produção de etanol no Brasil: tecnologias e práticas. 2009. Disponível em: <http://pt.slideshare.net/gilberto1096/aspectos-da-sustentabilidade-ambiental-da-producao-de-etanol-no-brasil- 
tecnologias-e-praticas>. Acesso em: 01 mar. 2017.

LEFF, Enrique. Racionalidad ambiental: La reapropriación social de la naturaleza. México: Siglo XXI Editores Vozes, 2004.

LEFF, Enrique. Saber ambiental. Petrópolis: Vozes, 2004.

MACEDO, Isaias. Uso de defensivos agrícolas. In: MACEDO, Isaias. $A$ energia da cana-de-açúcar: doze estudos sobre a agroindústria da canade-açúcar no Brasil e a sua sustentabilidade. São Paulo: ÚNICA, 2007.

NASSAR, André. M. et al. An allocation methodology to assess GHG emission associated with land use change - Final Report. ICONE - Institute for International trade Negotiations. September 2010. Disponível em: <http://www.iconebrasil.com.br/datafiles/publicacoes/estudos/2010/an_allocation_methodology_to_assess_ghg_emissions_0410.pdf $>$. Acesso em: 01 mar. 2017.

NEGRET, Rafael. El desarrollo sustenible como propuesta de la otra vía para América Latina y el Caribe. In: LEFF, Enrique; BASTIDA, Mindahi (Coords.). Comercio, medio ambiente y desarrollo sustentable: perspectivas de América Latina y el Caribe. México: PNUMA, 2001.

ORGANIZATION FOR ECONOMIC CO-OPERATION AND DEVELOPMENT. Air and GHG emissions. 2017. Disponível em: $<$ https://data.oecd.org/air/air-and-ghg-emissions.htm>. Acesso em: 01 mar. 2017.

PAIXÃO, Maria Cristina Silva; FONSECA, Márcia Batista da. A produção de etanol de cana no estado da Paraíba: alternativas de sustentabilidade. Revista Desenvolvimento e Meio Ambiente (UFPR). Curitiba-PR, v. 24, p. 171-184, 2011.

PARAÍBA (estado). Lei de n. ${ }^{\circ} 6.379$, de 02 de dezembro de 1996. Trata do Imposto sobre Operações Relativas à Circulação de Mercadorias e sobre Prestações de Serviços de Transporte Interestadual e Intermunicipal e de Comunicação - ICMS, e dá outras providências. Disponível em: $<\mathrm{http}: / /$ legisla.receita.pb.gov.br/LEGISLACAO/LEIS-ESTADUAIS/ICMS/LEI- 
6379-96-ICMS-INTEIRA/LEI-6379-96(INTEIRA)_.html>. Acesso em: 01 mar. 2017.

VEIGA FILHO, Alceu de Arruda. Novo ciclo do Proálcool: problemas derivados do aumento da produção do etanol. ComCiência: Revista Eletrônica de Jornalismo Científico. Campinas-SP, Dossiê Etanol, n. 86, 2007. Disponível em: <http://www.comciencia.br/comciencia/ ?section $=8 \&$ tipo $=$ dossie $\&$ edicao $=23>$. Acesso em: 01 mar. 2017.

VIEIRA, Maria Célia Azeredo; LIMA, Jaldir Freire; BRAGA, Natália Mesquita. Setor Sucroalcooleiro Brasileiro: Evolução e Perspectivas. Disponível em: <http://www.bndes.gov.br/SiteBNDES/export/sites/default/ bndes_pt/Galerias/Arquivos/conhecimento/liv_perspectivas/07.pdf>. Acesso em: 01 mar. 2017.

UNIÃO DA INDÚSTRIA DE CANA DE AÇÚCAR. $2 .^{\circ}$ Relatório de sustentabilidade do setor sucroenergético. Disponível em: $<$ http://www.unica.com.br/documentos/publicacoes/pag=2>. Acesso em: 01 mar. 2017.

Artigo recebido em: 04/03/2017. Artigo aceito em: 23/08/2017.

\section{Como citar este artigo (ABNT):}

RANGEL, Ana Celecina Lucena da Costa; CUNHA, Belinda Pereira da; CÂMARA, Renan Aversari. Crise da Racionalidade e Sustentabilidade no Mercado de Combustíveis no estado da Paraíba. Veredas do Direito, Belo Horizonte, v. 14, n. 29, p. 207-227, mai./ago. 2017. Disponível em: < http:// www.domhelder.edu.br/revista/index.php/veredas/article/view/1019>. Acesso em: dia mês. ano. 